\title{
Cloning and expression of PirA gene of Vibrio parahaemolyticus strain K5 causing acute hepatopancreatic necrosis disease in whiteleg shrimp in $E$. coli host cell
}

Nguyen Van Khanh1 (D) | Tran Quoc Dung² | Tran Quang Khanh Van ${ }^{3}$ Nguyen Quang Linh 3,4,5 (iD

${ }^{1}$ Laboratory of Enzyme and Protein Technology, Hue University, Hue city, Thua Thien Hue province, Vietnam

${ }^{2}$ Faculty of Biology, University of Education, Hue University, Hue city, Thua Thien Hue province, Vietnam

${ }^{3}$ Faculty of Fisheries, University of of Agriculture and Forestry, Hue University, Hue city, Thua Thien Hue province, Vietnam

${ }^{4}$ Faculty of Animal Science and Veterinary Medicine, University of Agriculture and Forestry, Hue University, Hue city, Thua Thien Hue province, Vietnam

${ }^{5}$ Hue University, 03 Le Loi St., Hue, Thua Thien Hue, 49000, Vietnam.

\section{Correspondence}

Nguyen Van Khanh, Laboratory of Enzyme and Protein Technology, Hue University, Hue city, Thua Thien Hue province, 530000, Vietnam.

Email: nvkhanh@hueuni.edu.vn

Nguyen Quang Linh, Hue University, 03 Le Loi St., Hue, Thua Thien Hue, 49000, Vietnam

Email: nguyenquanglinh@,hueuni.edu.vn

\begin{abstract}
Background: Acute hepatopancreatic necrosis disease (AHPND), is a bacterial disease of whiteleg shrimp, which has a high mortality rate (100\%) and incurs economic losses. Our objective was to identify the genes which lead to cell and organ damage and investigate bioproducts to prevent and treat. Methods: Litopenaeus vannamei shrimp in Thua Thien Hue province, Vietnam were collected from an infected pond and analysed at the Institute of Biotechnology, Hue University. The PirA gene of Vibrio parahaemolyticus strain K5 was isolated and analyzed for nucleotide sequence and paired with the expression vector $\mathrm{pQE} 30$. The expression vector was transformed into E. coli strain M15, the PirA recombinant protein was expressed in the form of 6xHis-PirA fusion protein of about $15 \mathrm{kDa}$. PirA recombinant protein was purified and determined the PirAvp binding ratio, cloning and sequencing of
\end{abstract}


PirA gene from Vibrio parahaemolyticus strain K5 causing AHPND by PCR method with specific primers and molecular weights of PirAvp and the PirAvp complex.

Results: PirA gene from Vibrio parahaemolyticus strain K5 was cloned into pGEM-T easy vector (Promega, USA) and screened E. coli TOP10 colonies containing pGEM T easy/PirA recombinant plasmid on LB agar/ampicillin/IPTG/X-Gal medium. PCR showing a band of about $347 \mathrm{bp}$, matching the size of PirA gene and two nucleotide sequences (BamHI and HindIII). The results showed that PirA gene has a length of $336 \mathrm{bp}$ and similar to PirA gene on GenBank (Code: KU556825.1). The results of protein extracted from E. coli M15 recombinant cells and 6xHis-PirA target protein was collected in elution fractions from EF2 to EF6, showed that the concentration of 6xHis-PirA protein and EF3 elution fraction collected a highest protein concentration $(1,586.54 \mu \mathrm{g} / \mathrm{ml})$.

Conclusions: The purified PirA recombinant protein will provide materials for development research to create biological products to prevent and treat AHPND.

KEYWORDS: Vibrio parahaemolyticus, PirA gene, Acute Hepatopancreatic Necrosis Disease, Shrimp

\section{Introduction}

Acute hepatopancreatic necrosis disease (AHPND), also known as early mortality syndrome or acute hepatopancreatic necrosis syndrome, is the disease caused by Vibrio strains and affects shrimp. AHPND was first detected in China in 2009 and spread throughout Southeast Asia to countries such as Thailand, Vietnam, Malaysia and the Philippines (Flegel, 2012; Leaño \& Mohan, 2012; Leobert et al., 2015; D. V. Lightner et al., 2013). In 2013, the disease was found in Mexico (Soto-Rodriguez, Gomez-Gil, Lozano-Olvera, Betancourt-Lozano, \& Morales-Covarrubias, 2015) and in other countries of Latin America between 2013 and 2015 (Han, Tang, \& Lightner, 2015). Outbreaks of AHPND disease have also been reported in Bangladesh (Eshik, Abedin, Punom, Begum, \& Rahman, 2017) and the United States (Dhar et al., 2019). Shrimp production in these countries has declined sharply (Shinn et al., 2018). AHPND is characterized by various clinical signs, including empty gastrointestinal tract, opaque white stomach, hepatopancreas atrophy, a pale color, lethargic swimming, stopping of eating, and soft shell (Leaño \& Mohan, 2012; N. N. Quang, Linh, Linh, \& Ha, 2013). The disease progresses rapidly, starting about 8 days after stocking, and highest mortality occurs during the first 20 to 30 days (up to $100 \%$ ) in Litopenaeus vannamei and Penaeus monodon populations (D V Lightner, Redman, Pantoja, Noble, \& Tran, 2012; Linh \& Tung, 2013), causing heavy economic losses of billions of dollars each year to shrimp farmers around the world (Dao, Linh, \& Khanh, 2014). Currently, there is no effective preventive measure.

One of AHPND pathogens has been identified as a specific strain of Vibrio parahaemolyticus (Tran et al., 2013). Quang et al. (2013) recorded the presence of $V$. parahaemolyticus and Vibrio alginolyticus with a very high density of $13.10^{6} \mathrm{CFU} / \mathrm{mg}$ from the hepatopancreas mass of whiteleg shrimps in Thua 
Thien Hue (Vietnam) with clinical signs of AHPND (N. N. Quang, et al., 2013). Dao et al. (2014) identified some characteristics of Vibrio parahaemolyticus strain V1 isolated from juvenile whiteleg shrimp showing clinical signs of AHPND in Thua Thien Hue. The study revealed it is Gram-negative bacterium, rod shaped, $0.3-0.5 \mu \mathrm{m}$ in width and $1.4-2.6 \mu \mathrm{m}$ in length. In addition, its colonies are mauve, round, smooth with a darker center than the surrounding on CHROM agar medium (Dao, et al., 2014). V. parahaemolyticus is mainly distributed in marine and estuarine environments around the world (Wang et al., 2015). The strains of AHPND pathogenic bacteria contain an intracellular plasmid, which is not found in non-pathogenic strains (Xiao et al., 2017). This large plasmid (69-70 kb) contains PirAvp and PirBvp toxin genes (Han, Tang, Tran, \& Lightner, 2015; Yang et al., 2014) that encode PirABvp binary protein, which has been shown to be the major virulence factor (Han, Tang, Tran, et al., 2015; Lee et al., 2015; Sirikharin et al., 2015). Quang et al. (2020) isolated 14 strains of Vibrio spp. carrying PirAvp and PirBvp genes from whiteleg shrimp samples cultured in Tam Giang lagoon (Vietnam) (Quang et al., 2020). From whiteleg shrimps infected AHPND in Phong Dien district, Thua Thien Hue province (Vietnam), we isolated $V$. parahaemolyticus strain K5 carrying both PirA and PirB toxin genes with predicted size of $336 \mathrm{bp}$ and $1,317 \mathrm{bp}$, respectively (Khanh et al., 2019)

In this study, we sequenced the PirA gene of the isolated $V$. parahaemolyticus strain K5, created E. coli M15 recombinant cells carrying $p Q E 30 /$ PirA recombinant plasmid as well as induced the expression of PirA recombinant protein in the form of $6 x H i s-P i r A$ fusion protein. Then, the recombinant antigen is purified to provide materials for further research to develop vaccines or antibodies against AHPND.

\section{Methods}

\section{Materials}

E. coli strain TOP10 (Promega, USA), E. coli strain M15 (Qiagen, Germany), pGEM-T-Easy vector (Promega, USA), pQE30 expression vector (Qiagen, Germany), PirA gene isolated from Vibrio parahaemolyticus strain K5 (Khanh, et al., 2019).

Chemicals: Tryptone (Biobasic, USA), peptone (Biobasic, USA), yeast extract (Biobasic, USA), NaCl (Merck, Germany), $\mathrm{KCl}$ (Merck, Germany), $\mathrm{MgCl}_{2}$ (Merck, Germany), $\mathrm{MgSO}_{4}$ (Merck, Germany), $\mathrm{K}_{2} \mathrm{HPO}_{4}$ (Merck, Germany); $\mathrm{KH}_{2} \mathrm{PO}_{4}$ (Merck, Germany), glycerol (Merck, Germany), Triton X-100 (Merck, Germany), imidazole (Sigma-Aldrich, USA), ampicillin (Biobasic, USA), kanamycin (Biobasic, USA), Isopropyl $\beta$-D-1-thiogalactopyranoside (IPTG, Biorad, USA), acrylamide (SigmaAldrich, USA), bis-acrylamide (Sigma-Aldrich, USA), Tris-HCl (Merck, Germany), tris base (Merck, Germany), $\mathrm{HCl}$ (Merck, Germany), sodium dodecyl sulfate (SDS, Bio-Rad, USA), Ammonium persulfate (APS, Bio-Rad, USA), N, N, N', N'-tetramethylethylenediamine (TEMED, Bio-Rad, USA), Tris (Bio-Rad, USA), 2-Mercaptoethanol (Bio-Rad, USA), Bromophenol Blue (Bio-Rad, USA), 
Glycine (Bio-Rad, USA), Coomassie Brilliant Blue R-250 (Bio-Rad, USA), methanol (Sigma-Aldrich, USA), glacial acetic acid (Merck, Germany), PageRulerTM Prestained Protein Ladder (10-170 kDa, Thermoscientific, USA), BamHI and HindIII restriction enzymes (Promega, USA), BamHI_PirA_1F and HindIII_PirA_336R primers (Phusa Biochem, Vietnam).

\section{Cloning and sequencing of PirA gene}

The PirA gene was isolated from Vibrio parahaemolyticus strain K5 causing AHPND on whiteleg shrimp by PCR method with specific primers. A shotgun sequencing of bacterial small subunit ribosomal DNA gene fragments amplified from AHPND infected shrimp revealed that the bacterial sequences of VpAHPND strains were not related to sequences normally found in diseased shrimp infected with other Vibrio bacterial species. A phylogenetic analysis showed that the strains were genetically diverse and not derived from a single genetic lineage. On the other hand, a preliminary sequence assembly and comparison analysis of the strains suggested that the target sequences originated from plasmid. The identified contigs of the strains were found to be homologous not to chromosomes of known $V$. parahaemolyticus but to the contigs obtained from other VpAHPND strains. Furthermore, a contig encodes the homologues of type IV pilus protein and conjugal transfer protein in the strain was also revealed, which suggests that it is located on a plasmid to insert the PirA gene into the $p Q E 30$ expression vector, specific primers BamHI and HindIII restriction enzymes were added (BamHI_PirA_1F forward primer: 5'-GGATCCATGAGTAACAATATAAAACATG-3'; HindIII_PirA_336R reverse primer: 5'-AAGCTTAGTGGTAATAGATTGTACAG-3').

PCR was carried out in $12 \mu \mathrm{l}$ reactions containing $1 \mu \mathrm{l}$ of genomic DNA template, $1 \mu \mathrm{l}$ of each primer (10 pmol), $6 \mu$ of $2 \mathrm{X}$ GoTaq ${ }^{\circledR}$ Green Master Mix (Promega, USA) and $4 \mu$ l of nuclease-free water for the amplication of the pirA gene. The reactions were run on MJ MiniTM Personal Thermal Cycler (BioRad, USA). PirA gene was amplified using the following parameters: initial denaturation at $95^{\circ} \mathrm{C}$ for 5 minutes, 30 cycles of $95^{\circ} \mathrm{C}$ for 30 seconds, $53^{\circ} \mathrm{C}$ for 30 seconds and $72^{\circ} \mathrm{C}$ for 1 minute 30 seconds, followed by a final extension at $72^{\circ} \mathrm{C}$ for 10 minutes and store at $4^{\circ} \mathrm{C}$. The PCR product was electrophoresed on a $1 \%$ agarose gel, voltage of $80 \mathrm{~V}$ in $1 \mathrm{X}$ TAE buffer with SafeView dye (1X TAE: SafeView $=20: 1$ ). Electrophoresis result was observed on Ultra Slim LED Illuminator (Miulab, China).

The PCR product was cloned in pGEM®-T easy vector and transformed into E.coli TOP10 host cells by heat shock method (Froger \& Hall, 2007). The E. coli were grown for 24 to $36 \mathrm{~h}$ on LB (NaCl 10 $\mathrm{g} / \mathrm{L}$, Yeast extract $5 \mathrm{~g} / \mathrm{L}$, Peptone $10 \mathrm{~g} / \mathrm{L}$ ) agar medium supplemented with $100 \mu \mathrm{g} / \mathrm{ml}$ ampicillin +100 $\mathrm{mM}$ IPTG $+200 \mathrm{mg} / \mathrm{ml} \mathrm{X-Gal} \mathrm{(LB} \mathrm{agar/ampicillin/IPTG/X-Gal} \mathrm{medium)} \mathrm{and} \mathrm{the} \mathrm{best} \mathrm{grown} \mathrm{were}$ selected. Five white colonies were randomly selected and PCR with BamHI_PirA_1F and HindIII_PirA_336R primers to screen E. coli cells containing pGEM-T easy/PirA recombinant plasmid was performed. The recombinant plasmid was isolated from E. coli cells using EZ-10 Spin Column

Plasmid DNA Mini-preps Kit (Biobasic, USA). PirA gene from $p G E M-T$ easy/PirA plasmid were 
sequenced by Sanger's method with specific primers (T7 promoter: 5'TAATACGACTCACTATAGGG-3' and SP6Long: 5'- ATTTAGGTGACACTATAGAATAC-3') (Firstbase, Malaysia). The pirA gene sequencing was performed by First TBASE Laboratories Sdn Bhd (Selangor, Malaysia) after cloning. The sequences of PirA gene were analyzed by BioEdit software (ver 7.0.5.3) and compared with PirA gene sequences published on GenBank (accession number: KU556825.1) using the BLAST program.

\section{Insertion PirA gene into expression vector}

Recombinant $p G E M-T$ easy/PirA plasmid and $p Q E 30$ expression vector were extracted from E. coli TOP10 cells and digested by BamHI and HindIII restriction enzymes (incubated at $37^{\circ} \mathrm{C}$ for 4 hours). Subsequently, the digest products were electrophoresed on 2\% agarose gel, $p Q E 30$ vector and PirA gene were collected from gel and purified by ISOLATE II PCR and Gel Kit (Bioline, UK). The two purified products were ligated by T4 DNA ligase (Biobasic, USA) according to the molar ratio between $p Q E 30$ vector and PirA gene, which is $1: 3$, at $22^{\circ} \mathrm{C}$ for 1 hour to form a $p Q E 30 /$ PirA recombinant plasmid. Then the $p Q E 30 / P i r A$ was transformed into E. coli TOP10 cells using the heat shock method before selection on LB agar medium supplemented with $100 \mu \mathrm{g} / \mathrm{ml}$ ampicillin. We screened $E$. coli TOP10 cells containing pQE30/PirA recombinant plasmid by colony PCR method with BamHI_PirA_1F and HindIII_PirA_336R primers, as described in the previous section (See Cloning and Sequencing of pirA gene).

\section{Creation of E. coli M15 cells containing recombinant pQE30/PirA plasmid}

Recombinant $p Q E 30 /$ PirA plasmid was extracted from E. coli TOP10 cells by EZ-10 Spin Column Plasmid DNA Mini-preps Kit (Biobasic, USA) and transformed into E. coli strain M15 cells by heat shock method (Froger \& Hall, 2007). Five transformed colonies grown on LB agar supplemented with $100 \mathrm{~g} / \mathrm{ml}$ ampicillin and $50 \mathrm{~g} / \mathrm{ml}$ kanamycin were randomly selected and further cultured in liquid LB medium supplemented with $100 \mathrm{~g} / \mathrm{ml}$ ampicillin and $50 \mu \mathrm{g} / \mathrm{ml}$ ampicillin for recombinant plasmid extraction. Recombinant $p Q E 30 /$ PirA plasmids were extracted and checked for the presence of PirA gene by PCR with BamHI_PirA_1F and HindIII_PirA_336R primers, as described previously. E. coli M15 cells carrying recombinant $p Q E 30 /$ PirA plasmid were selected for PirA gene expression.

\section{Expression of recombinant PirA protein}

E. coli M15 cells containing recombinant expression vector were cultured in $5 \mathrm{ml}$ of LB medium supplemented with $100 \mathrm{mg} / \mathrm{L}$ ampicillin and $50 \mathrm{mg} / \mathrm{L}$ kanamycin, shaken at $180 \mathrm{rpm}$ overnight at $37^{\circ} \mathrm{C}$. Culture solution was transfered into $250-\mathrm{mL}$ erlenmeyer flasks containing $100 \mathrm{ml}$ of $\mathrm{LB} /$ ampicillin/kanamicin medium $(4 \% \mathrm{v} / \mathrm{v})$, incubated at $37^{\circ} \mathrm{C}$ with shaking speed of $200 \mathrm{rpm}$. For optimization of recombinant PirA antigen expression, cultivations were performed under different IPTG (isopropyl- $\beta$-D- hiogalactopyranoside) concentrations. In order to optimize IPTG concentration for recombinant PirA antigen expression in E. coli M15, different IPTG concentrations (0.1-1.0 mM) were 
added and cultured after reaching the desired OD600nm of 1.0 at $37^{\circ} \mathrm{C}, 200 \mathrm{rpm}$. The samples were collected after 4 hours of the induction.

Cell density was determined by measuring the optical absorbance of a sample at $600 \mathrm{~nm}\left(\mathrm{OD}_{600 \mathrm{~nm}}\right)$ on the double beam spectrophotometer U-2900 (HITACHI, Japan).

\section{Extraction of recombinant antigens and sodium dodecyl sulfate-polyacrylamide gel electrophoresis (SDS-PAGE)}

The recombinant $E$. coli $\mathrm{M} 15$ cell biomass was collected by centrifugation at 12,000 rpm for 2 minutes and then re-suspended in a Lysis buffer $(50 \mathrm{mM}$ potassium phosphate $(\mathrm{pH}=7.8), 400 \mathrm{mM} \mathrm{NaCl}, 100$ $\mathrm{mM} \mathrm{KCl}, 10 \%$ glycerol, $0.5 \%$ Triton X-100, $10 \mathrm{mM}$ imidazole). The cell was homogenized by ultrasonic cell disruptor with 05 cycles ( 60 seconds of ultrasound and 30 seconds of rest), on sonicator at a frequency of $20 \mathrm{khz}$. Next, the sample was centrifuged at 12,000 rpm for 10 minutes to separate soluble and insoluble proteins. The supernatant was collected and assayed on 15\% SDS-PAGE gel. The gel was stained with Coomassie Brilliant Blue for 30 minutes. Finally, the gel was washed with a washing solution $(30 \%(\mathrm{v} / \mathrm{v})$ methanol, $10 \%(\mathrm{v} / \mathrm{v})$ acetic acid) until the gel became clear and protein bands appear (blue).

The recombinant E. coli M15 colony with high PirA expression was collected and used for the next experiments. The cells were cultured in the above conditions for the recombinant PirA gene expresstion. Recombinant PirA solution as purified by HisTrap FF column (GE Healthcare, USA) according to the manufacturer's instructions. The purified protein concentration was determined by the Bradford method (Bradford, 1976).

\section{Data analysis}

Data were statistically analyzed using Minitab software version 16.2.0 and Microsoft Excel 2013 to calculate the mean and standard deviation. ANOVA was used to identify significantly different means compared between elution fractions with Tukey's test at a probability level of $\mathrm{P} \leq 0.05$.

\section{Results}

\section{Sequencing of PirA gene}

Amplification product of PirA gene from Vibrio parahaemolyticus strain K5 was cloned into pGEM-T easy vector (Promega, USA). We screened E. coli TOP10 colonies containing $p G E M T$ easy/PirA recombinant plasmid on LB agar/ampicillin/IPTG/X-Gal medium. To confirm the presence of PirA gene in E. coli TOP10 colonies, five white colonies were randomly selected to conduct colony PCR with BamHI_PirA_1F and HindIII_PirA_336R primers. The PCR product electrophoresis showed a band of about $347 \mathrm{bp}$, matching the size of PirA gene, and two nucleotide sequences of BamHI and 
HindIII restriction enzymes according to theoretical calculations in the protocol. Next, two E. coli TOP10 colonies containing $p$ GEM T easy/PirA recombinant plasmid were selected for extraction of the recombinant plasmid that provided material for the nucleotide sequence analysis of PirA gene. The results of PirA gene sequencing are shown in Figure 1.

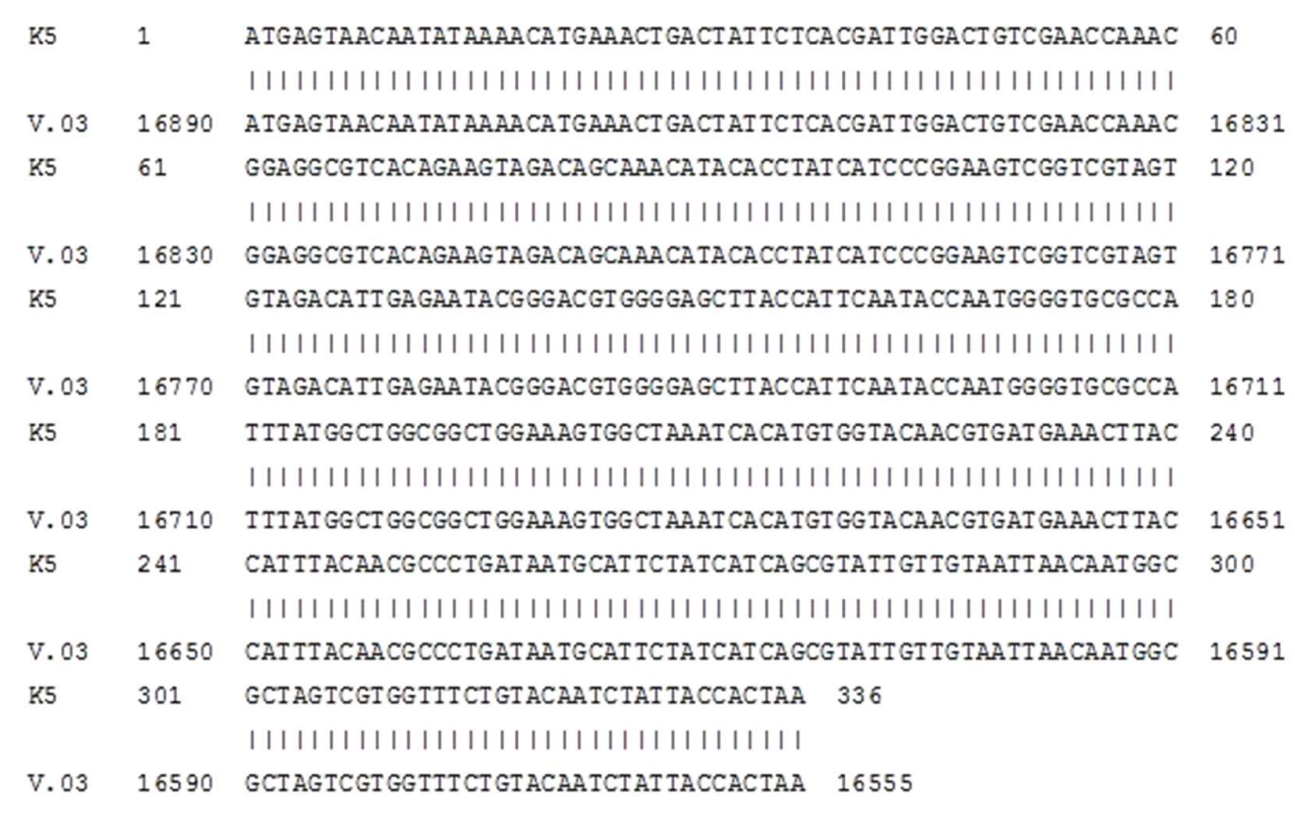

FIGURE 1. Comparison of the nucleotides sequence of the PirA gene from Vibrio parahaemolyticus strain K5 and Vibrio parahaemolyticus strain V.03 (KU556825.1) on GenBank.

The analysis results showed that PirA gene has a length of $336 \mathrm{bp}$ (Figure 1) (excluding two recognizable nucleotide sequences of BamHI enzyme at the 5 'end and the HindIII enzyme at the 3 ' end) and PirA gene sequence from Vibrio parahaemolyticus strain K5 is 100\% similar to PirA gene from Vibrio parahaemolyticus strain V.03 which has been published on GenBank (accession number: KU556825.1).

\section{Creation pQE30/PirA recombinant plasmid}

The PirA gene and $p Q E 30$ vector were collected and purified from digestion products by BamHI and HindIII restriction enzymes, after $p Q E 30$ vector and PirA gene were paired by the enzyme T4 DNA ligase to create $p Q E 30 /$ PirA recombinant plasmid. The coupling product was then transformed into $E$. coli strain TOP10 and first screened on LB Agar medium supplemented with 100ug/ml ampicillin. The transformation result showed that white colonies appeared on LB agar/ampicillin medium (Figure 2A). This indicates a successful transformation, and these colonies may contain $p Q E 30 /$ PirA recombinant plasmid. We randomly selected five colonies for biomass culture and plasmid extraction. PCR was performed with the extracted DNA plasmid template, and BamHI_PirA_1F and HindIII_PirA_336R 
primers to confirm the presence of PirA gene. The PCR product was electrophoresed on $1 \%$ agarose gel (Figure 2B).
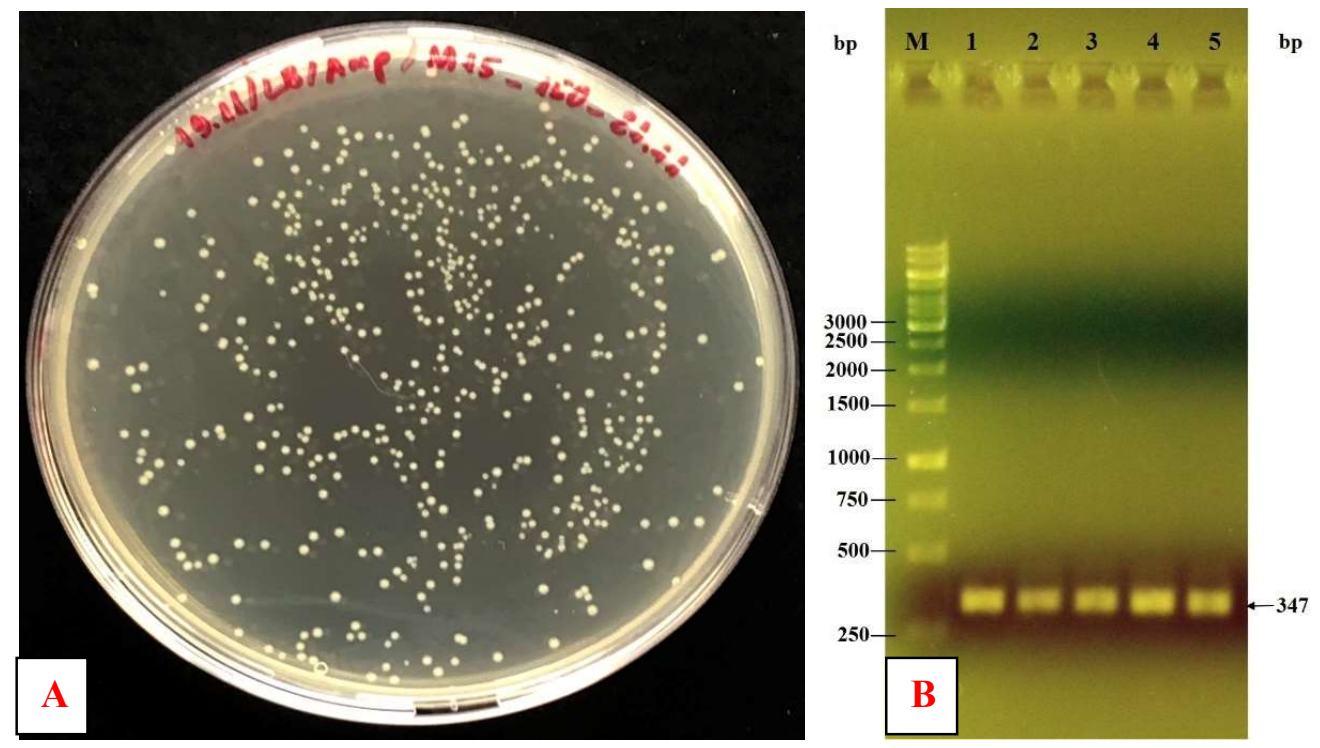

FIGURE 2. Results of transformation of $p Q E 30 /$ PirA recombinant plasmid into E. coli strain M15 cells. (A) E. coli M15 colonies - results of transformation of $p Q E 30 / P i r A$ recombinant plasmid; (B) Electrophoresis of PCR products of PirA gene from 05 E. coli M15 colonies - results of transformation of $p Q E 30 /$ PirA recombinant plasmid.

The results of the study showed that PCR products from five selected colonies all appeared as bands with of about $350 \mathrm{bp}$, matching the size of the PirA gene (336 bp) with addition of the recognizable nucleotide sequences of BamHI enzyme at the 5 'end and HindIII enzyme at the 3 ' end.

\section{PirA recombinant antigen expression in $E$. coli}

The $p Q E 30$ expression vector carrying PirA gene was transformed into E. coli M15 cells by heat shock method. The transformed cells were selected randomly to extract recombinant plasmid and to check for the presence of the target gene (PirA) by PCR with BamHI_PirA_1F and HindIII_PirA_336R primers. The PCR products were electrophoresed on 1\% agarose gel and showed the appearance of DNA bands with the size of about $347 \mathrm{bp}$, matching the size of PirA gene with addition of the recognizable nucleotide sequences of BamHI and HindIII enzymes (Figure 2B) The results showed that $p Q E 30 /$ PirA recombinant plasmid was successfully transformed into $E$. coli $\mathrm{M} 15$ cells.

E. coli M15 cells carrying $p Q E 30 /$ PirA recombinant plasmid were cultured and induced PirA antigen expression by IPTG. The SDS-PAGE electrophoresis results (Figure 3) showed that the protein fraction 
obtained in the experimental group was about $15 \mathrm{kDa}$, and this protein fraction did not appear in the control group - E. coli M15 cells did not carry pQE30/PirA recombinant plasmid.

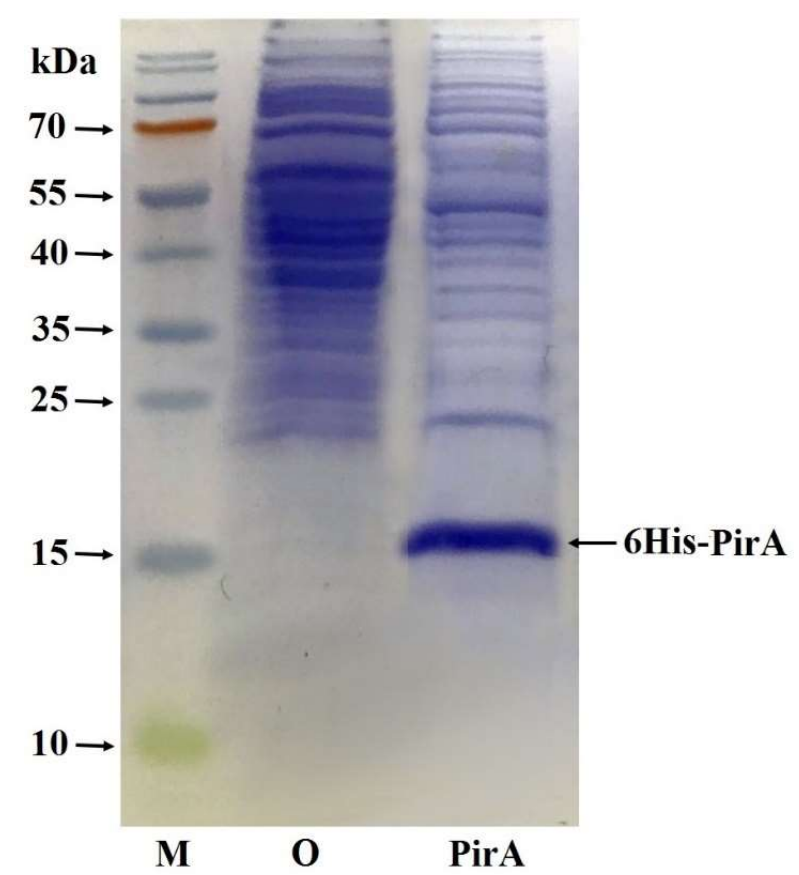

FIGURE 3. Results of SDS-PAGE electrophoresis of PirA recombinant antigen expression in E. coli M15 cells. M: PageRuler TM Prestained Protein Ladder (10-170 kDa, Thermoscientific); O: E. coli M15 cells did not carry $p Q E 30 /$ PirA recombinant plasmid; PirA: E. coli M15 cells carry $p Q E 30 /$ PirA recombinant plasmid.

\section{PirA recombinant antigen purification}

To confirm the presence of PirA antigens fused with the 6xHis tag, total protein of E. coli M15 recombinant cells was used as material for the purification of the PirA-6xHis fusion protein by affinity chromatography method with HisTrap FF column (GE Healthcare, USA). The results of electrophoresis on the $15 \%$ SDS-PAGE gel (Figure 4) showed that 6xHis-PirA fusion protein was recovered in a purified form, with the size of about $15 \mathrm{kDa}$ matching to the theoretical size. Thus, the study result confirmed that PirA gene was successfully expressed in 6xHis-PirA fusion protein form. 


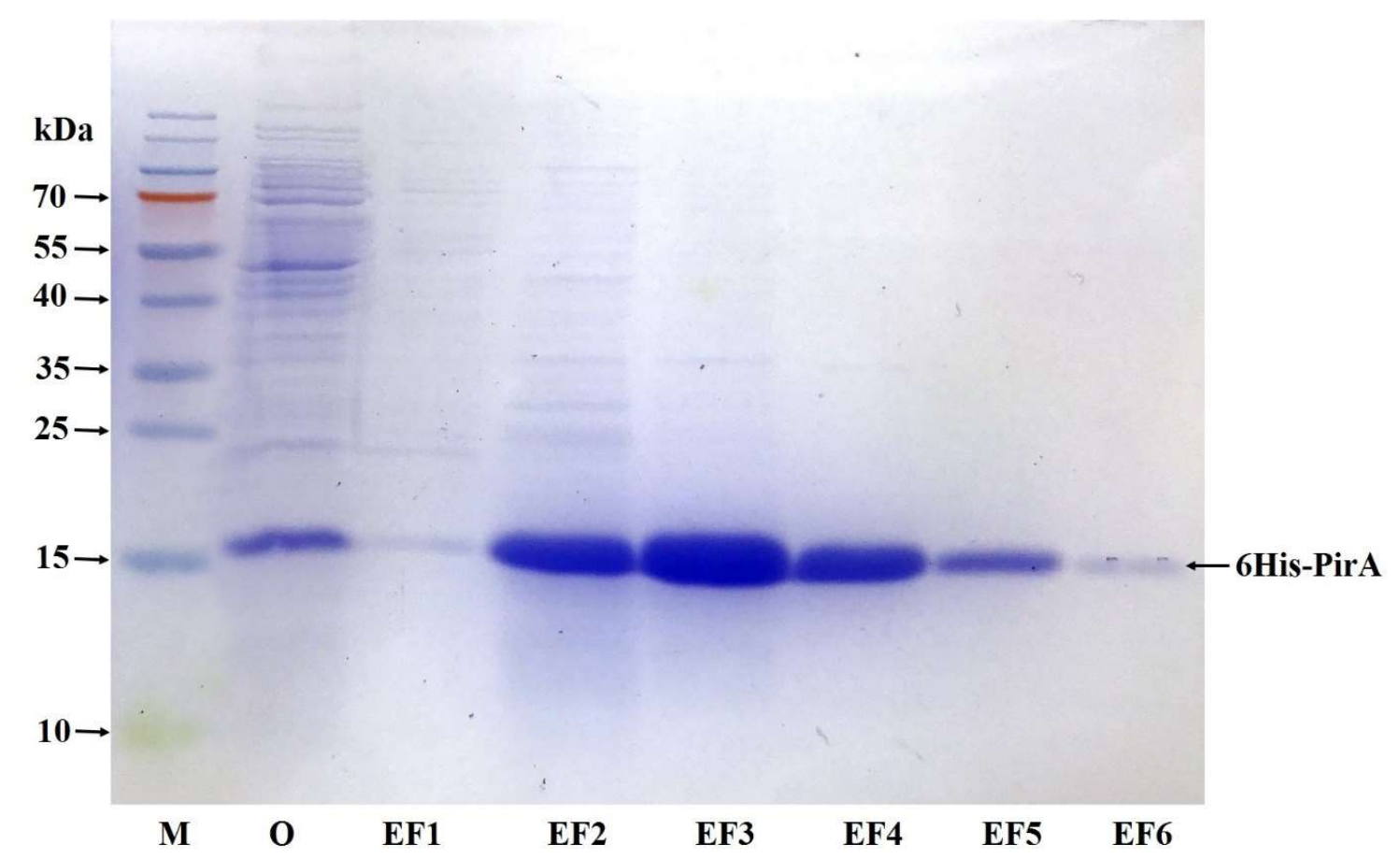

FIGURE 4. Electrophoresis of 6xHis-PirA fusion protein after purification with HisTrap FF column. M: PageRuler TM Prestained Protein Ladder (10-170 kDa, Thermoscientific); O: the total protein of $E$. coli M15 recombinant cells; EF1 to EF5: 6xHis-PirA fused protein in elution fractions (1-5) from HisTrap FF column.

The SDS PAGE electrophoresis result (Figure 4) for the total protein extracted from E. coli M15 recombinant cells and 6xHis-PirA target protein in elution fractions from the HisTrap FF column (EF1 - EF6) with Elution buffer (20 mM sodium phosphate, $0.5 \mathrm{M} \mathrm{NaCl}, 0.5 \mathrm{M}$ imidazole, $\mathrm{pH}$ 7.4) showed that the majority of 6xHis-PirA fusion protein was collected in elution fractions from EF2 to EF6, while most of the basic proteins of E. coli M15 that was unable to bind to $\mathrm{Ni}^{2+}$ ions on the HisTrap FF column were removed during wash step with the binding buffer $(20 \mathrm{mM}$ sodium phosphate, $0.5 \mathrm{M} \mathrm{NaCl}, 5 \mathrm{mM}$ imidazole) previously. Most of the protein 6xHis-PirA binding on the column was collected from EF2 to EF5 elution fractions, while 6xHis-PirA protein was collected very little at EF1 and EF6 elution fractions. Thus, the 6xHis-PirA protein has been purified successfully. However, there is still a small amount of impurity protein in the purified product in EF1 and EF2 elution fractions.

Analytical results by Bradford method (Table 1) showed that the concentration of 6xHis-PirA protein in elution fractions from HisTrap FF column was different. In which, EF3 elution fraction collected the highest target protein concentration $(1,586.54 \mu \mathrm{g} / \mathrm{ml})$, followed by EF2 elution fraction $(1,317.1 \mu \mathrm{g} / \mathrm{ml})$. The collected protein concentrations decreased gradually from EF3 to EF6 elution fractions, reaching the lowest in EF6 $(17.46 \mu \mathrm{g} / \mathrm{ml})$. 
TABLE 1. 6xHis-PirA fusion protein concentration was collected in elution fractions from HisTrap FF column $(\mu \mathrm{g} / \mathrm{ml})$

\begin{tabular}{ccccccc}
\hline $\begin{array}{c}\text { Elution } \\
\text { fractions }\end{array}$ & EF1 & EF2 & EF3 & EF4 & EF5 & EF6 \\
\hline $\begin{array}{c}\text { 6xHis-PirA } \\
\text { fusion protein } \\
\text { concentration }\end{array}$ & $\begin{array}{c}67.92 \pm \\
1.21^{\mathrm{e}}\end{array}$ & $\begin{array}{c}1,317.14 \pm \\
6.27^{\mathrm{b}}\end{array}$ & $\begin{array}{c}1,586.54 \pm \\
5.53^{\mathrm{a}}\end{array}$ & $\begin{array}{c}1,001.09 \pm \\
2.17^{\mathrm{c}}\end{array}$ & $\begin{array}{c}354.04 \pm \\
0.60^{\mathrm{d}}\end{array}$ & $\begin{array}{r}17.46 \pm \\
0.60^{\mathrm{f}}\end{array}$ \\
\hline
\end{tabular}

Note: The means with different letters within the same row are significantly different between elution fractions at the 0.05 probability level.

\section{Discussion}

The PirA gene sequence in this study is similar to those of Almanza-Martínez et al's. (2015) analysis of $V$. parahaemolyticus strains causing AHPND isolated in Baja California Sur and Sinaloa (Mexico). That study showed that these strains carry the PirAvp gene with the size of 336 bp (Almanza-Martínez, Martínez-Díaz, \& Cardona-Félix, 2016). Results of genomic analysis of $V$. parahaemolyticus strain MSR16 and $V$. parahaemolyticus strain MSR17 isolated from Penaeus monodon in southwestern Bangladesh showed that both strains carry the plasmid ( $\sim 69 \mathrm{Kbp}$ ), which contained PirA and PirB toxin genes. The PirA gene's size was 336 bp (starting at position 64,962 bp and ending at position 65,297 bp on the plasmid of MSR16 strain; starting at position 63,108 bp and ending at position 63,443 bp on the plasmid of MSR17 strain) (Ahmmed et al., 2019). The results of genomic analysis of $V$. parahaemolyticus strain 13-028/A3 showed that the toxin proteins were encoded by two 2 genes (pirAlike and pirB-like) in a segment $3.5 \mathrm{~kb}$, the pirA-like gene (336 bp) and the pirB-like gene (1,317 bp) encoded for $13 \mathrm{kDa}$ and $50 \mathrm{kDa}$ proteins, respectively (Han, et al., 2015).

There are several protein expression systems for production of recombinant proteins such as bacterial, yeast, insect, mammalian systems. In this study, E. coli strain M15 was used as a host cell to express PirA antigen of Vibrio parahaemolyticus strain K5 because of E. coli's outstanding properties including easy manipulation, inexpensive culture medium and rapid growth (Baeshen et al., 2015; Francis \& Page, 2010; Ghosh et al., 2004; Gomes, Monteiro, \& Mergulhão, 2020; Jia \& Jeon, 2016; Joseph et al., 2015; Rosano \& Ceccarelli, 2014; Vaz et al., 2011), high performance of recombinant protein expression (Francis \& Page, 2010) and easy collection target proteins (Kaur, Kumar, \& Kaur, 2018). In addition, antigens synthesized by E.coli host cells are suitable materials for antibody production (Rancour, Backues, \& Bednarek, 2010). Numerous studies have been performed to optimize the expression conditions of recombinant proteins in E. coli (Abath, Xavier, Silva, Junior, \& Montenegro, 1997; Arévalo-Herrera et al., 2015; Hu et al., 2004; Vaz, et al., 2011; Zhao et al., 2011).

Our research results showed that the expression of PirA gene was produced in the form of a fusion protein with high concentration. The molecular weight of this fusion protein was approximately $15 \mathrm{kDa}$ (including 6xHis tag of $p Q E 30$ vector) (Figure 3). This size is higher than found in study by Han et al. (2015), where proteomic analysis showed that the pirA-like genes (336 bp) encode for a protein with the size of $13 \mathrm{kDa}$ (Han, et al., 2015). Lee et al. (2015) performed western blot analysis with antibodies 
against PirA $^{v p}$ from AHPND causing $V$. parahaemolyticus and found that this strain secreted PirA ${ }^{v p}$ (12 $\mathrm{kDa}$ ) into the culture medium after $1 \mathrm{~h}$ after cultivation (Lee, et al., 2015). The variation in the size of the PirA protein may be due to the influence of several factors during SDS PAGE electrophoresis and the effect of the expression system on PirA gene expression.

The PirA antigen was expressed by $p Q E 30$ expressing vector system and was fused with six amino acids histidine. This $6 \mathrm{xHis}$ tag has a high affinity for $\mathrm{Ni}^{+}$ions on the Histrap FF column (GE Healthcare, USA), allowing for easy collection of 6xHis-PirA fusion protein and removal of other proteins of E. coli M15 cell when their total proteins are passed through the chromatographic column. The 6xHis-PirA fusion protein recovered from the Histrap FF column had high purity and concentration (Figure 4 and Table 1), and can be used as a raw material for further research to produce antibodies to prevent AHPND in shrimp caused by Vibrio spp.

\section{Conclusions}

The study results showed that PirA gene of Vibrio parahaemolyticus strain K5 was successfully cloned in pGEM-T easy vector. The PirA gene is $336 \mathrm{bp}$ in size and $100 \%$ similar to the nucleotide sequence of PirA gene of Vibrio parahaemolyticus strain V.03 that has been published on GenBank (KU556825.1). The PirA gene was successfully inserted into a $p Q E 30$ expression vector. The PirA recombinant antigen was expressed as a 6xHis-PirA fusion protein (about 15kDa) in E. coli strain M15 and the purified protein was obtained at high concentrations by affinity chromatography method with HisTrap FF column. The purified PirA recombinant protein can be used as raw material for further research to develop antibodies to prevent acute hepatopancreatic necrosis disease in shrimp.

\section{Data availability}

https://csdlkhoahoc.hueuni.edu.vn/index.php/topic/index/user/109/page/1, lience of Ministry of Education and Training, Vietnam.

Cloning and expression of PirA gene of Vibrio parahaemolyticus strain K5 causing acute hepatopancreatic necrosis disease in whiteleg shrimp in E. coli host cell

- 1st_BASE_3641594_A4(K5) T7promoter.ab1: The nucleotide peaks of pirA gene form T7 promoter primer from Vibrio parahaemolyticus strain K5 causing AHPND in whiteleg shrimp in Phong Dien district, Thua Thien Hue province, Vietnam.

- 1st_BASE_3641594_A4(K5)_T7promoter.seq: The nucleotide sequence of pirA gene form T7 promoter primer from Vibrio parahaemolyticus strain K5 causing AHPND in whiteleg shrimp in Phong Dien district, Thua Thien Hue province, Vietnam. 
- 1st_BASE_3641598_A4(K5)_SP6Long.ab1: The nucleotide peaks of pirA gene form SP6Long primer from Vibrio parahaemolyticus strain K5 causing AHPND in whiteleg shrimp in Phong Dien district, Thua Thien Hue province, Vietnam.

- 1st_BASE_3641598_A4(K5)_SP6Long.seq: The nucleotide sequence of pirA gene form SP6Long primer from Vibrio parahaemolyticus strain K5 causing AHPND in whiteleg shrimp in Phong Dien district, Thua Thien Hue province, Vietnam.

- 6xHis-PirA_fusion_protein_concentration.xlsx: Concentrations of 6xHis-PirA fusion protein extracted from E. coli $\mathrm{M} 15$ recombinant cells.

\section{Competing interests}

No competing interests were disclosed.

\section{Grant information}

This investigation was funded by the Ministry of Education and Training, Vietnam, through a ministrylevel science and technology project (reference: CT2018-DHH-04).

\section{ORCID}

Nguyen Quang Linh (D) https://orcid.org/0000-0002-8424-1148

Nguyen Van Khanh (D) https://orcid.org/0000-0002-2115-8603

\section{References}

Abath, F. G., Xavier, E. M., Silva, J. D. A. B., Junior, M. A. M., \& Montenegro, S. M. (1997). Expression of recombinant antigens in Escherichia coli: application on immunochemical studies of Schistosoma mansoni tegumental antigens. Memórias do Instituto Oswaldo Cruz, 92, 637-641. doi: https://doi.org/10.1590/S0074-02761997000500014.

Ahmmed, S., Khan, M. A.-A.-K., Eshik, M. M. E., Punom, N. J., Islam, A. B. M. M. K., \& Rahman, M. S. (2019). Genomic and evolutionary features of two AHPND positive Vibrio parahaemolyticus strains isolated from shrimp (Penaeus monodon) of south-west Bangladesh. BMC microbiology, 19(1), 1-14. doi: 10.1186/s12866-019-1655-8

Almanza-Martínez, N., Martínez-Díaz, S. F., \& Cardona-Félix, C. S. (2016). Molecular identification of Vibrio parahaemolyticus strains responsible of Acute Hepatopancreatic Necrosis Disease. 3rd Biotechnology Summit 2016, Ciudad Obregón, Sonora, Mexico, 24-28 October 2016, 8387. doi: https://doi.org/10.3329/dujbs.v27i1.46411

Arévalo-Herrera, M., Vallejo, A. F., Rubiano, K., Solarte, Y., Marin, C., Castellanos, A., . . Herrera, S. (2015). Recombinant Pvs 48/45 antigen expressed in E. coli generates antibodies that block 
malaria transmission in Anopheles albimanus mosquitoes. PloS one, 10(3), e0119335. doi: 10.1371/journal.pone.0119335

Baeshen, M. N., Al-Hejin, A. M., Bora, R. S., Ahmed, M., Ramadan, H., Saini, K. S., . . Redwan, E. M. (2015). Production of biopharmaceuticals in E. coli: current scenario and future perspectives. J Microbiol Biotechnol, 25(7), 953-962. doi: 10.4014/jmb.1412.12079

Bradford, M. M. (1976). A rapid and sensitive method for the quantitation of microgram quantities of protein utilizing the principle of protein-dye binding. Analytical biochemistry, 72(1-2), 248254. doi: $\underline{10.1006 / \text { abio.1976.9999 }}$

Dao, N. T. B., Linh, N. Q., \& Khanh, N. V. (2014). Research some of characteristics of Vibrio parahaemolyticus which causes ems disease on juvenile shrimp at Dien Huong community, Phong Dien district, Thua Thien Hue province. Journal of Science - Hue University, 98(10), $13-22$.

Dhar, A. K., Piamsomboon, P., Caro, L. F. A., Kanrar, S., Adami Jr, R., \& Juan, Y.-S. (2019). First report of acute hepatopancreatic necrosis disease (AHPND) occurring in the USA. Diseases of Aquatic Organisms, 132(3), 241-247. doi: 10.3354/dao03330

Eshik, M. M. E., Abedin, M. M., Punom, N. J., Begum, M. K., \& Rahman, M. S. (2017). Molecular identification of AHPND positive Vibrio parahaemolyticus causing an outbreak in south-west shrimp farming regions of Bangladesh. Journal of Bangladesh Academy of Sciences, 41(2), 127-135. doi: https://doi.org/10.3329/jbas.v41i2.35492

Flegel, T. W. (2012). Historic emergence, impact and current status of shrimp pathogens in Asia. Journal of invertebrate pathology, 110(2), 166-173. doi: https://doi.org/10.1016/j.jip.2012.03.004

Francis, D. M., \& Page, R. (2010). Strategies to optimize protein expression in E. coli. Current protocols in protein science, 61(1), 5.24. 21-25.24. 29. doi: 10.1002/0471140864.ps0524s61

Froger, A., \& Hall, J. E. (2007). Transformation of plasmid DNA into E. coli using the heat shock method. JoVE (Journal of Visualized Experiments)(6), e253. doi: 10.3791/253

Ghosh, S., Rasheedi, S., Rahim, S. S., Banerjee, S., Choudhary, R. K., Chakhaiyar, P., . . Hasnain, S. E. (2004). Method for enhancing solubility of the expressed recombinant proteins in Escherichia coli. Biotechniques, 37(3), 418-423. doi: 10.2144/04373ST07

Gomes, L., Monteiro, G., \& Mergulhão, F. (2020). The Impact of IPTG Induction on Plasmid Stability and Heterologous Protein Expression by Escherichia coli Biofilms. International journal of molecular sciences, 21(2), 576. doi: 10.3390/ijms21020576 
Han, J. E., Tang, K. F., \& Lightner, D. V. (2015). Genotyping of virulence plasmid from Vibrio parahaemolyticus isolates causing acute hepatopancreatic necrosis disease in shrimp. Diseases of Aquatic Organisms, 115(3), 245-251. doi: 10.3354/dao02906

Han, J. E., Tang, K. F., Tran, L. H., \& Lightner, D. V. (2015). Photorhabdus insect-related (Pir) toxinlike genes in a plasmid of Vibrio parahaemolyticus, the causative agent of acute hepatopancreatic necrosis disease (AHPND) of shrimp. Diseases of Aquatic Organisms, 113(1), 33-40.

Hu, P. Q., Tuma-Warrino, R. J., Bryan, M. A., Mitchell, K. G., Higgins, D. E., Watkins, S. C., \& Salter, R. D. (2004). Escherichia coli expressing recombinant antigen and listeriolysin O stimulate class I-restricted CD8+ T cells following uptake by human APC. The Journal of Immunology, 172(3), 1595-1601. doi: DOI: https://doi.org/10.4049/jimmunol.172.3.1595

Jia, B., \& Jeon, C. O. (2016). High-throughput recombinant protein expression in Escherichia coli: current status and future perspectives. Open biology, 6(8), 160196. doi: 10.1098/rsob.160196

Joseph, B. C., Pichaimuthu, S., Srimeenakshi, S., Murthy, M., Selvakumar, K., Ganesan, M., \& Manjunath, S. R. (2015). An overview of the parameters for recombinant protein expression in Escherichia coli. Journal of Cell Science \& Therapy, 6(5), 1. doi: 10.4172/2157-7013.1000221

Kaur, J., Kumar, A., \& Kaur, J. (2018). Strategies for optimization of heterologous protein expression in E. coli: Roadblocks and reinforcements. International journal of biological macromolecules, 106, 803-822. doi: 10.1016/j.ijbiomac.2017.08.080

Khanh, N. V., Linh, N. Q., Lan, T. T., Van, T. Q. K., Co, N. T. K., \& Dung, T. Q. (2019). Isolation and screening of Vibrio parahaemolyticus strains to cause acute hepatopancreatic necrosis disease in white-leg shrimps cultured in Phong Dien, Thua Thien Hue using 16S rRNA marker. Hue University Journal of Science: Natural Science, 128(1E), 47-58. (In Vietnamese)

Leaño, E. M., \& Mohan, C. V. (2012). Early mortality syndrome threatens Asia's shrimp farms. Global Aquaculture Advocate, 2012(7/8), 38-39.

Lee, C. T., Chen, I. T., Yang, Y. T., Ko, T. P., Huang, Y. T., Huang, J. Y., . . Lin, S. S. (2015). The opportunistic marine pathogen Vibrio parahaemolyticus becomes virulent by acquiring a plasmid that expresses a deadly toxin. Proceedings of the National Academy of Sciences, 112(34), 10798-10803.

Leobert, D., Cabillon, N. A. R., Catedral, D. D., Amar, E. C., Usero, R. C., Monotilla, W. D., . . . Saloma, C. P. (2015). Acute hepatopancreatic necrosis disease (AHPND) outbreaks in Penaeus vannamei and P. monodon cultured in the Philippines. Diseases of Aquatic Organisms, 116(3), 251-254. 
Lightner, D. V., Redman, C. R., Pantoja, B. L., Noble, L. M., Nunan, L. T., \& Tran, L. (2013). Documentation of an Emerging Disease (early mortality syndrome) in SE Asia \& Mexico. OIE Reference Laboratory for Shrimp Diseases, Department of Veterinary Science \& Microbiology, School of Animal and Comparative Biomedical Sciences.

Lightner, D. V., Redman, R. M., Pantoja, C. R., Noble, B. L., \& Tran, L. (2012). Early mortality syndrome affects shrimp in Asia. Global Aquaculture Advocate, 15(1), 40.

Linh, N. Q., \& Tung, H. T. (2013). Alternatives and isolation of Bacillus strains for inbition of Vibrio parahaemolyticus on early mortality syndome of shrimp. Paper presented at the Asian-Pacific Aquaculture 2013, Ho Chi Minh City, Vietnam.

Quang, H. T., Lan, T. T., Hai, T. T. H., Yen, P. T. H., Van, T. Q. K., Tung, H. T., . . Tram, N. D. Q. (2020). Genetic diversity and toxic genes analysis of Vibrio spp. isolated from white leg shrimp and marine fishes cultured in Tam Giang lagoon in Thua Thien Hue province, Vietnam. Indian Journal of Science and Technology, 13(13), 1412-1422. doi: https://doi.org/10.17485/IJST/v13i13.161

Quang, N. N., Linh, N. Q., Linh, N. T. H., \& Ha, T. N. (2013). Research on necrotizing hepatopancreatitis in pacific white shrimp cultured in Thua Thien- Hue province. Science and Technology Journal of Agriculture \& Rural Development, Ministry of Agriculture and Rural Development, Vietnam(17), 69-76. (In Vietnamese)

Rancour, D. M., Backues, S. K., \& Bednarek, S. Y. (2010). Protein antigen expression in Escherichia coli for antibody production. Methods Mol Biol, 657, 3-20. doi: https://doi.org/10.1007/978-160761-783-9 1

Rosano, G. L., \& Ceccarelli, E. A. (2014). Recombinant protein expression in Escherichia coli: advances and challenges. Frontiers in microbiology, 5, 172. doi: https://doi.org/10.3389/fmicb.2014.00172

Shinn, A. P., Pratoomyot, J., Griffiths, D., Trong, T. Q., Vu, N. T., Jiravanichpaisal, P., \& Briggs, M. (2018). Asian shrimp production and the economic costs of disease. Asian Fish. Sci. S, 31, 2958.

Sirikharin, R., Taengchaiyaphum, S., Sanguanrut, P., Chi, T. D., Mavichak, R., Proespraiwong, P., .. . Sritunyalucksana, K. (2015). Characterization and PCR detection of binary, Pir-like toxins from Vibrio parahaemolyticus isolates that cause acute hepatopancreatic necrosis disease (AHPND) in shrimp. PloS one, 10(5), e0126987.

Soto-Rodriguez, S. A., Gomez-Gil, B., Lozano-Olvera, R., Betancourt-Lozano, M., \& MoralesCovarrubias, M. S. (2015). Field and experimental evidence of Vibrio parahaemolyticus as the 
causative agent of acute hepatopancreatic necrosis disease of cultured shrimp (Litopenaeus vannamei) in Northwestern Mexico. Appl. Environ. Microbiol., 81(5), 1689-1699.

Tran, L., Nunan, L., Redman, R. M., Mohney, L. L., Pantoja, C. R., Fitzsimmons, K., \& Lightner, D. V. (2013). Determination of the infectious nature of the agent of acute hepatopancreatic necrosis syndrome affecting penaeid shrimp. Diseases of Aquatic Organisms, 105(1), 45-55.

Vaz, M. R. F., França, R. L. S. d., Andrade, S. S. L. d., Sousa Junior, F. C. d., Santos, E. S. d., Martins, D. R. A., \& Macedo, G. R. d. (2011). Influence of culture medium on the production of eif antigen from Leishmania chagasi in recombinant Escherichia coli. Brazilian Journal of Microbiology, 42(4), 1390-1396. doi: https://doi.org/10.1590/S1517-83822011000400021

Wang, R., Zhong, Y., Gu, X., Yuan, J., Saeed, A. F., \& Wang, S. (2015). The pathogenesis, detection, and prevention of Vibrio parahaemolyticus. Frontiers in microbiology, 6, 144.

Xiao, J., Liu, L., Ke, Y., Li, X., Liu, Y., Pan, Y., .. Wang, Y. (2017). Shrimp AHPND-causing plasmids encoding the PirAB toxins as mediated by pirAB-Tn903 are prevalent in various Vibrio species. [Article]. Scientific Reports, 7, 42177. doi: 10.1038/srep42177

Yang, Y.-T., Chen, I.-T., Lee, C.-T., Chen, C.-Y., Lin, S.-S., Hor, L.-I., . . Thitamadee, S. (2014). Draft genome sequences of four strains of Vibrio parahaemolyticus, three of which cause early mortality syndrome/acute hepatopancreatic necrosis disease in shrimp in China and Thailand. Genome Announc., 2(5), e00816-00814.

Zhao, Y., Wang, C., Lu, Y., Amer, S., Xu, P., Wang, J., . . He, H. (2011). Prokaryotic expression and identification of 3-1E gene of merozoite surface antigen of Eimeria acervulina. Parasitology research, 109(5), 1361-1365. doi: 10.1007/s00436-011-2381-9

Lawrence D., F. Clement, D. Gillespie, D. Kurnitfi: Evidence for evolution by nonrandom unequal crossovers (satellite DNA/nucleosome/heterochromatin/primates). Section on Molecular Hybridization, Laboratory of Tumor Cell Biology, National Cancer Institute, Bethesda, Maryland 20205. 1980, Vol. 77, No. 4, pp. 2129-2133, April 1980 Genetics DNA sequence of baboon highly repeated DNA: 